\section{Antibody Response to Pneumococcal Polysaccharide Vaccine in Systemic Sclerosis}

\section{To the Editor:}

Systemic sclerosis ( $\mathrm{SSc}$ ) is a connective tissue disorder characterized by cutaneous and visceral fibrosis, and obliterative vasculopathy. The lungs are frequently affected in SSc, and pulmonary disease may significantly influence morbidity and mortality ${ }^{1}$. Patients with SSc are at increased risk for microbial infections due to the immune effects of the disease itself, and the frequent use of immunosuppressive agents. Current guidelines recommend vaccination with pneumococcal polysaccharide for persons 2 to 64 years of age with chronic illness and for persons 65 years of age or older ${ }^{2,3}$. Therefore, vaccination might be useful in this infection-prone population provided that the vaccines produce a significant increase in antibody levels. To date, antibody responses to pneumococcal polysaccharide vaccine in patients with SSc are unknown. We evaluated the immunogenicity of this commercial vaccine in patients with SSc during promotional campaigns.

Eighteen consecutive patients with SSc, according to the American College of Rheumatology criteria ${ }^{4}$, attending our outpatient clinic were included. Patients were grouped in subsets as defined by LeRoy, et $a l^{5}$. Patients who had received pneumococcus vaccination within 5 years prior to study were excluded. There were 17 women and one man of median age 46.5 years (range 31-62) and median disease duration 7.5 years (range 1-12). Diffuse cutaneous SSc (dcSSc) was present in 12 patients and limited cutaneous $\mathrm{SSc}(\mathrm{lcSSc})$ in 6 . Antibody against DNA topoisomerase I was positive in 10 patients and 3 patients had anticentromere antibody. The mean modified Rodnan skin score was 16.7 (range 8-32). At the time of vaccination, $2 \mathrm{SSc}$ patients had received intravenous cyclophosphamide, 5 were receiving low-dose prednisone $(2.5-5.0 \mathrm{mg} /$ day $), 5$ colchicine, and one D-penicillamine. Metoclopramide, proton-pump inhibitors, and vasodilators were a part of their drug therapy.

Each patient received an intradeltoid injection with $0.5 \mathrm{ml}$ pneumococcal vaccine (23-valent Pulmovax; Merck Sharp \& Dohme). Antibody concentrations to 4 antigens $(4,6 \mathrm{~B}, 12 \mathrm{~F}$, and 14; American Type Culture Collection, Manassas, VA, USA) were measured by enzyme-immunoassay. These serotypes represent those most frequently encountered in our region. Serum samples were collected prior to and 4 weeks after vaccination administration.

Capsular antigens were bound to 96-well polystyrene microtiter plates at $0.5 \mu \mathrm{g}$ per $100 \mu 1$ phosphate-buffered saline (PBS) per well by overnight incubation at $4^{\circ} \mathrm{C}$. Sera were applied to plates at initial dilution of 1:100 in $1 \%$ bovine serum albumin with $0.05 \%$ Tween 20 in PBS. Bound antibodies were detected with a conjugated probe, followed by substrate addition. The levels of each specific antibody were calculated relative to the amount of color development. A $\geq 2$-fold rise in antibody titer was considerated as a protective response.

Differences in antibody titers before and after vaccination were calculated by Wilcoxon signed-rank test. Differences in median antibody levels between patients with lcSSc and dcSSc were investigated by Mann-Whitney U-test. A p value $<0.05$ was considerated significant. The fold-rise in serotype-specific IgG was calculated for each subject as the postvaccination titer divided by the prevaccination titer. The percentage of patients with $\geq 2$-fold increases in antibody levels was analyzed.

Mean antibody levels to the 4 different pneumococcal capsular polysaccharides before and 4 weeks after vaccination are shown in Table 1 . Prior to vaccination, mean antibody levels ranged from 48 to $70 \mathrm{ng} / \mathrm{ml}$. One month after vaccination, mean levels increased significantly to the 4 capsular antigens (range 127 to $169 \mathrm{ng} / \mathrm{ml} ; \mathrm{p}<0.05$ ). On average, antibody titers rose from 2.3 (for capsular antigen $12 \mathrm{~F}$ ) to 3.3 (for capsular antigen $6 \mathrm{~B}) . \mathrm{A} \geq 2$-fold rise in antibody titer to at least one capsular antigen was achieved by $100 \%$ of patients, and $83 \%$ achieved a $\geq 2$-fold rise to $\geq 3$ of 4 capsular antigens.

Among the cyclophosphamide-treated patients, one achieved a $\geq 2$-fold rise to serotypes 4,6 , and $14(2.9,4.0$, and 2.0 , respectively), whereas in the other patient, serotypes 4 and 14 were the most immunogenic (3.4 and 2.0 , respectively). No significant difference in the median pneumococcal antibody titers pre- and postvaccination was observed between patients with lcSSc and those with dcSSc (Table 2).

We also investigated the persistence of protective pneumococcal antibodies in 10 subjects one year after administration of pneumococcal polysaccharide vaccine; all showed mean decreased antibody levels, compared with mean postvaccination antibody levels (Table 1). None had pneumonia or renal crisis. Two patients had pain at the injection site.

We observed that the patients with SSc developed a protective antibody response to the 4 capsular antigens tested. A $\geq 2$-fold rise in titer to one serotype was achieved by $100 \%$ of the patients, and to 3 or more serotypes by $83 \%$ of patients, including patients taking immunosuppressive drugs. The followup of 10 out of 18 patients with SSc at 1 year, however, revealed mean antibody levels lower than postvaccination levels. Previously, the author critically reviewed the literature on vaccination in rheumatic diseases and evaluated the effect of pneumococcal vaccine in patients with systemic lupus erythematosus (SLE). In that study, 3 out of 4 capsular antigens were also tested (12F, 6B, and 14). One month after vaccine administration, 9 of 12 patients achieved a $\geq 2$-fold rise in titer of protective antibodies ${ }^{6,7}$.

Other investigators ${ }^{8,9}$ have reported that pneumococcal vaccinations in patients with SLE and other chronic rheumatic diseases were safe and immunogenic, albeit lower than in controls. We did not investigate whether

Table 2. Median antibody levels before and after pneumococcal vaccination (nanograms IgG per ml) between $\operatorname{lcSSc}(\mathrm{n}=6)$ and dcSSc $(\mathrm{n}=12)$ patients.

\begin{tabular}{lcccc}
\hline & Serotype 4 & Serotype 6 & Serotype 12 & Serotype 14 \\
\hline Prevaccination & 60.5 vs 73 & 50 vs 45 & 65 vs 40 & 38.5 vs 60 \\
Postvaccination & 131 vs 191 & 144 vs 111 & 148.5 vs 103 & 129 vs 156 \\
p & NS & NS & NS & NS \\
\hline
\end{tabular}

NS: nonsignificant.

Table 1. Antibody levels before and after pneumococcal vaccination (nanograms IgG per $\mathrm{ml}$ ) and number (\%) of patients with $\geq 2$-fold rise in antibody levels.

\begin{tabular}{lcccccc}
\hline $\begin{array}{l}\text { Pneumococcal } \\
\text { Capsular Type }\end{array}$ & $\begin{array}{c}\text { Prevaccination } \\
\text { (mean) }\end{array}$ & $\begin{array}{c}4 \text { Weeks } \\
\text { Postvaccination } \\
\text { (mean) }\end{array}$ & p & $\begin{array}{c}\text { 2-fold Rise } \\
\text { (mean) }\end{array}$ & $\begin{array}{c}\geq 2 \text {-fold Rise, } \\
\mathrm{n}(\%)\end{array}$ & $\begin{array}{c}\text { At 1 Year* } \\
\text { (mean) }\end{array}$ \\
\hline 4 & $70 \pm 31$ & $169 \pm 67$ & 0.0002 & 3.0 & $14(78)$ & $102 \pm 61$ \\
6B & $48 \pm 19$ & $142 \pm 77$ & 0.0002 & 3.3 & $15(83)$ & $86 \pm 35$ \\
12F & $50 \pm 22$ & $127 \pm 59$ & 0.0001 & 2.3 & $13(72)$ & $97 \pm 57$ \\
14 & $58 \pm 25$ & $152 \pm 48$ & 0.0001 & 2.8 & $16(89)$ & $86 \pm 40$ \\
\hline
\end{tabular}

* Nanograms IgG per milliliter. 
pneumococcal vaccine in SSc patients triggers the generation of disease-specific autoantibodies and/or clinical exacerbation of SSc. To date, there is no evidence of a pathogenic relationship between systemic autoimmunity and the clinical features of $\mathrm{SSc}^{10}$. According to Hudson, et $a l^{11}$, who critically reviewed the literature on global measures of disease activity in SSc, there is currently no gold standard measure of disease activity in SSc.

Our study had the following limitations: small number of patients, the lack of a control group, and the absence of safety assessment. However, we showed (1) that both lcSSc and dcSSc patients generated protective antibody levels in similar form to the 4 antigens tested at 1 month after vaccination; (2) that $83 \%$ of the patients achieved protective antibody levels to 3 or more capsular antigens; and (3) that the antibody response was independent of treatment with immunosuppressive drugs.

ULISES MERCADO, MD; HECTOR ACOSTA, MS; RAUL

DIAZ-MOLINA, PhD, Hospital General Mexicali, and Universidad

Autonoma of Baja California, Mexicali, Mexico. Address reprint requests to Dr. Mercado; E-mail: ulisesmercado@uabc.mx

\section{REFERENCES}

1. Silver RM, Miller KS. Lung involvement in systemic sclerosis. Rheum Dis Clin N Am 1990;16:199-216.

2. Centers for Disease Control and Prevention. Prevention of pneumococcal disease: recommendation of the Advisory Committee on Immunization Practices (ACIP). MMWR Morb Mortal Wkly Rep 1977;45:1-24.

3. Whitney CG. Preventing pneumococcal disease. ACIP recommends pneumococcal polysaccharide vaccine for all adults age $\geq 65$. Geriatrics 2003;58:20-2; 25.

4. Subcommittee for scleroderma criteria of the American Rheumatism Association Diagnostic and Therapeutic Criteria Committee. Preliminary criteria for the classification of systemic sclerosis (scleroderma). Arthritis Rheum 1980;23:581-90.

5. LeRoy EC, Krieg T, Black CM, et al. Scleroderma (systemic sclerosis): classification, subsets, and pathogenesis. J Rheumatol 1988;15:202-5.

6. Mercado U. Antibody responses following vaccination in lupus patients. Rev Invest Clin 2003;55:93-4.

7. Mercado U. Why have rheumatologists been reluctant to vaccinate patients with systemic lupus erythematosus [editorial]. J Rheumatol 2006;33:1469-71.

8. Elkayam O, Paran D, Burke M, et al. Pneumococcal vaccination of patients with systemic lupus erythematosus: Effects on generation of autoantibodies. Autoimmunity 2005:38:493-6.

9. Mease PJ, Ritchlin CT, Martin RW, et al. Pneumococcal vaccine response in psoriatic arthritis patients during treatment with etanercept. J Rheumatol 2004;31:1356-61.

10. Arnett FC. Is scleroderma an autoantibody mediated disease? Curr Opin Rheumatol 2006;18:579-81.

11. Hudson M, Steele R; Canadian Scleroderma Research Group (CSRG), Baron M. Update on indices of disease activity in systemic sclerosis. Semin Arthritis Rheum 2007;37:93-8.

J Rheumatol 2009;36:7; doi.10.3899/jrheum.081227 